\title{
Basic Components of Developing Teachers' Research Competence as a Condition to Improve Their Competitiveness
}

\author{
Nina A. Ivanenko ${ }^{1}$, Gulshat M. Mustafina ${ }^{2}$, Viktoriya R. Sagitova ${ }^{3}$, Ildar G. Akhmetzyanov², Firuza V. \\ Khazratova $^{4}$, Ilsiya T. Salakhova ${ }^{5} \&$ Ekaterina V. Mokeyeva ${ }^{2}$ \\ ${ }^{1}$ Technical College at Kazan National Research Technical University named after A. N. Tupolev, Kazan, Russia, \\ ${ }^{2}$ Kazan (Volga region) Federal University, Kazan, Russia \\ ${ }^{3}$ Kazan Cooperative Institute (Branch) of the Russian University of Cooperation, Kazan, Russia \\ ${ }^{4}$ Naberezhnye Chelny Institute of Social-Pedagogical Technologies and Resources, Naberezhnye Chelny, Russia \\ ${ }^{5}$ Kazan State Conservatoire (Academy) named after N. Zhiganov, Kazan, Russia \\ Correspondence: Nina A. Ivanenko, Technica College at Kazan National Research Technical University \\ named after A. N. Tupolev, K. Marks Street 10, Kazan, 420111, Tatarstan, Russia. E-mail: \\ nina.ivanienko@mail.ru
}

Received: December 29, $2014 \quad$ Accepted: January 22, 2015 Online Published: February 11, 2015

doi:10.5539/res.v7n4p221 URL: http://dx.doi.org/10.5539/res.v7n4p221

\begin{abstract}
The problem of contemporary teachers' commitment to research activities is regarded as an essential condition to improve their competitiveness. In this respect, this article aims to disclose the basic components of developing the research competence of vocational education institutions teachers. The article deals with the nature and content of such basic components of developing teachers' research competence as motivational-value, methodological-reflexive, operational-activity, and emotional-volitional components. The presented components of developing teachers' research competence are aimed at ensuring integrity and continuity of a competitive as a subject teacher formation process, integrating research and professional activities. The article submissions are both of academic and practical importance for teachers of secondary and higher professional education, as well as for students of teacher training professions of higher and secondary professional education institutions.
\end{abstract}

Keywords: research competence, teachers, basic components, the competitiveness of a teacher

\section{Introduction}

In the context of studying the problem of improving competitiveness of professional education institution teachers it should most likely be about teachers' finding and developing innovative projects, research developments. In this case, the professional activities of teachers in secondary vocational schools, but as well as of modern university teachers should include a research component as a characteristic of his/her willingness to innovate, which implies susceptibility to innovations, based on a high level of a teacher's research competence formation, the ability to mobilize the personal-professional capacity of the required quantity and quality (Obukhov, 1999; Talyzina, 1986; Ryndina, 2011).

But for the competitiveness of a higher school teacher productive characteristics of the research process are more important than the procedural ones, that is, to possess certain knowledge enabling to estimate anything, give a weighty, authoritative opinion, awareness, authoritativeness in a certain area, or as a set of inter-related personality traits and the ability (skills) to implement complex types of actions.

This problem - is a problem of combination and separation of teaching and research activities of college teachers acquired an acute urgency since the moment when teacher training was carried out mainly on the basis of postgraduate study.

Social development of a teacher's personality is based on the priority of scientific knowledge application, which invariably involves orientation to a new result and its implementation, the economic effect, the mastery of integrative methodology of professional activities, formation of abilities to predict and design. The problem of contemporary teachers' commitment to research activities is regarded as an essential condition to improve their competitiveness. 
For all the apparent significance and relevance of this issue at the present time there is a variety of approaches to defining the essence of research competence, but there is no common understanding of it. Most researchers tend to view research competence of students as a result of well-planned research activities (statement and analysis of experimental results, writing research papers, etc.).

Some scholars identify it with innovative competence implying the use of basic innovative approaches and methods in any professional field. However, they are different types of competence (Ivanov et al., 2015).

Innovative competence of a subject is defined by at least two components: innovative interpretation of the fundamental units adopted in this area of activity (professionally-educative); capability of productive changing the elements of innovative activity and its object as a whole in accordance with the purpose.

The combination of "innovative specialist competence" is self-contradictory. The predicate "innovative" refers not only to the ability of a subject for creative activity, but also to his/her possession of original competencies to carry out the intended operation out of necessity, that is, depending on the situation. Therefore, this concept implicitly separates all teachers into two groups: those who are capable of certain professionally-educative activities; professionals, who, in addition to the basic training, acquire new professional competencies expressed in the implemented capability for innovative creative work. Hence the "innovation competence" concept expresses particularly high quality state of the innovation subject (Shaimakova, 2009).

\section{Literature Review}

The concept of research competence at the everyday life level can be associated with the ability to search for an answer to a creative, research problem with an unknown solution, which involves mastery of the basic stages of activities, which are characteristic for research in the scientific field. A. A. Ushakov under "research competence" understands the integral quality of personality, reflected in the willingness and ability to independently find solutions to new problems and creative transformation of reality based on the totality of personally-meaningful knowledge, capabilities, skills, ways of life and value systems (Ushakov, 2008).

In addition, there are very different interpretations of this concept:

- Research competence is regarded as the ability and research skills related to the analysis and evaluation of scientific material (Plotnikova, 2007);

- Research competence - is a special functional system of the psyche and the related integrated set of a person's qualities providing him/her with the opportunity to be an effective subject of this activity (Berezhnova, 2007).

According to Eleseeva, L. V., Kotova, G. L., Khutorskoy, A. V., and others, a model of the research competence formation structure (Khutorskoy, 2003), includes three interrelated components: methodologically-reflexive, motivational, communicative:

- Methodologically-reflexive component is treated as a body of knowledge and concepts necessary for the researcher to formulate and solve research problems in their professional activities, analysis and control of their scientific research and its results;

- Motivational component - this is the meaning that the research activity has not for all in general, but for an individual;

- Communicative component is seen as a set of skills that allow obtaining and transmission of scientific knowledge.

In the content of research competence there are the following competencies:

1) Competencies in acquiring knowledge: the ability to systematize, analyze scientific information; highlight the main structural elements of the scientific knowledge system in the text (facts, concepts, laws, theories and methods of scientific research and applicative knowledge); to apply plans of generalized character (algorithms) in the process of self-study of the basic structural elements of the scientific knowledge system; transfer information from one form to another (e.g., from a text to a scheme); compare and contrast the presentation of the same questions in different sources; express their opinions; create a relationship of knowledge and ensure its systematization; be able to use cognitive abilities in solving scientific problems at the analytically-synthetic level; master the mass media and multimedia technologies, e-mail, Internet technologies to solve scientific problems; be fluent in foreign languages; have competencies in the area of humanities and social sciences (have knowledge and skills in humanities), be willing to continuously update the knowledge and skills;

2) Competencies in anticipation of the results, in hypothesizing: have challenging worldviews in various knowledge spheres and on this basis to formulate the target, objectives of the research; be able to form a 
hypothesis in the study of phenomena, laws, carry out the inductive hypothesis formation on the basis of facts, phenomena known from mundane and everyday life experience, derived from observation, and experiment;

3) Competencies in selecting optimal solutions to the problem and their implementation: the ability to self-organize the expected ways of solving problems; analyze the resources to conduct research, to independently choose the necessary equipment and materials; to plan in detail all the phases of the study, substantiate and defend personal opinions; to describe extensively, analyze intermediate results of scientific research; be capable of using research methods;

4) Competencies in critical evaluation and explanation of the obtained results: to interpret the obtained results according to a particular theory; be able to process the results of studies, constructively assess their validity and possible errors made during the research (Morozova \& Fadeeva, 2007).

In the studies of O. V. Rakitina the following general (essential with the same type of character changes, manifested at all levels of education, professional and academic teaching activities) prerequisites were identified for forming scientific research competence:

1) At each stage of the educational and professional activities the development of scientific-research competence is realized both due to the formation of invariant nature competencies (manifested at all levels of education and teaching), and through the acquisition of specialized competencies, for the first time emerging at a certain stage. These competencies are at close unity and integration. Competencies, developing at a preliminary stage and relating to the area of the current development of the scientific-research activity subject, are a prerequisite for the subsequent formation of scientific-research competence (SRC).

2) Development of scientific-research competence is heterochronic, has an intrasystem character and is expressed in a heterogeneous embedding and the mistiming development phases of individual functional blocks of scientific-research competencies. At each stage in the professionalization of scientific-research activities various units of competencies have mainly their own development. The main problem in this regard remains a slower pace of formation of the motivational component part in the structure of the scientific competence of a specialist. Meanwhile, exactly the motivational component is specifically the main characteristic of the competence.

3) Development of scientific-research competence is cumulative, which is manifested in the fact that competencies first develop quite apart, and further are integrated into the system with a lot of links.

To private (similar changes in the scientific-research competence, appearing only in the scientific and teaching activities) the researcher refers the following prerequisites for developing scientific-research competencies of higher education institution teachers:

1) Development of scientific-research competence is not implemented progressively (with respect to education levels and previous professional activities) but as if built "anew", being reconstructed at the initial stage of scientific-educational activities.

2) The structure of scientific-research competence reaches a high degree of integration only with teachers having a scientific degree, i.e. those, who in their personal experiences have independent actions in performing scientific-research works, which make considerably high demands on the performers.

3) Increasing a teacher's scientific-research competence is largely determined by the system of professional education and self-education, and only to a small extent this development is determined by socio-demographic characteristics of the subject.

4) Most essential objective characteristics that reflect the competence of teachers in the field of scientific-research works are the total number of publications, the number of scientific articles, monographs, as well as their scientific projects, received grants, contests, and etc.

5) The development level of scientific-research competence of teachers with a scientific degree is higher than of those who do not have degrees.

6) Science degree of a teacher has a much greater significance for developing scientific-research competence, rather than their job titles.

7) Male teachers tend to evaluate their level of world outlook and learning in the research subject area as significantly higher than female teachers do.

8) Female teachers note a great degree of autonomy in tracking personal change and correction of their professional and scientific positions. 
9) With age, a teacher raises his/her competence in the area of goal formation in scientific activity.

The level of competencies development in the area of self-control increases with age and with experience as a teacher. As the main factor increasing the competitiveness of a university teacher J. B. Shaimakova highlights his/her innovative expertise, in the structure of which she identifies the following competencies:

- Methodological and epistemological (methodological reflection of a subject, the selection of appropriate methods for the purpose of innovation; ability to holistically analyze the changing socio-economic processes; the ability to effectively search, process and analyze heterogeneous information; and the ability to research and practically use the results of basic and applied investigations);

- Technological (ability to perceive innovation analytically and shift it into the language of practice-oriented productive activities in the form of algorithm, program, technology, procedure and other creative practices; ability to work in the interaction space of natural, technical and social sciences, in the mastery of scientific research methods in applied field, in the ability to translate theory into the language of technical-project-design activity and summarize the latter at the level of practice-oriented knowledge in terms of the problem being solved);

- Designing (the ability to translate the experience of practice-innovation activities into theoretical form; the ability to foresee the future of innovation; mastery of activity project forms);

- Practical (innovative susceptibility of the subject and successful adaptation to innovation; a special selective attitude to the object of innovative changing as a result of correlation, ranging ways of solving problems on the grounds of optimality; the availability of practical innovative skills) (Shaimakova, 2009).

Based on the qualification requirements to masters of engineering and technology, as well as on the social mandate for a modern competitive specialist, S. I. Dvoretsky and E. I. Muratova developed the content of the following readiness for scientific-research activity components of masters in technical areas:

- Motivational, that is, the motives formedness: understanding the nature of scientific-research and scientific-pedagogical activity; awareness of the importance of the acquired knowledge and skills for effective professional activity; satisfaction with creative work in the innovative scientific-research and scientific-pedagogical activity; willingness to participate in scientific conferences, seminars, publish the results of research; awareness of the need for lifelong self-learning and self-development for a successful career;

- Cognitive, i.e. the Master must know: the methodology of scientific and pedagogical research; methodology of scientific and technical work; foundations of applied research activities for the implementation of research development results, design and presentation of projects; principles of work, specifications, design features of the equipment, devices and systems used in the course of professional work; prospects for technological development and characteristics of the institution, organization, and enterprise activities; fundamentals of the economy, organization of production, labor and management; foundations of educational psychology, learning theory, methods and means of teaching engineering and technological disciplines, innovation in education;

- Operational, i.e. the Master must: possess skills of independent scientific-research and scientific-pedagogical activity, requiring a broad education in the appropriate area; formulate and solve problems arising in the course of scientific-research and teaching activities, and requiring in-depth professional knowledge; choose appropriate research methods, modify the existing ones and develop new methods based on the objectives of a particular research; be skilled in planning, conducting engineering experiment, data processing and analysis of experimental studies; have a good command of team management methods; be skilled in teaching and educational work; be skilled in design and supply of materials on the results of scientific research to participate in academic competitions, grants, bring the findings of scientific research to the development and implementation in practice;

- Emotional-volitional, assuming responsibility for the results of scientific-research and scientific-pedagogical activity; confidence in the success of achieving the goals of scientific research; volition to overcome internal and external obstacles in addressing research and educational tasks; volition to overcome the fear of failure, misunderstanding by the audience, fear of criticism; determination to mobilize strength to address the scientific-research and scientific-pedagogical problems; to control themselves in the process of research and teaching;

- Informational, that is, master's willingness to conduct bibliographic work and patent search, search for information on innovative projects using modern information technologies; create and use software products for processing the obtained results of a study, of mathematical experiments on the study; present the results of the work done in the form of reports, reviews, articles, drawn up in accordance with present requirements, using 
modern means of editing and printing; use modern information technology and network for effective communication with colleagues from various universities, including foreign ones, on the issue of research.

- Develop and use electronic products and tools for teaching technical disciplines in the process of teaching, as well as for monitoring and evaluation of students' knowledge (Dvoretsky and Muratova, 2004).

O. P. Khodenkova developed a model of a university teacher's key competencies, being formed under the influence of post-graduate education (Khodenkova, 2011). In the competence model of the faculty, formed under the influence of postgraduate education system, the researcher considers the following groups of competencies:

- Functional group of key competencies includes gnostic (mastery of the system of knowledge required to successfully complete the professional and managerial skills, implemented in professional and educational sphere;

- A group of scientific-pedagogical competencies acts as organizationally-technological characteristic and lies in the formation of skills to organize the educational process; a set of pedagogical and professional knowledge according to the studied profession;

- Personal component (personal competencies) is presented by such personality traits as reflection, flexibility, empathy, sociability, ability to cooperate, emotional appeal;

- Ethical competencies are based on the perception of higher school behavioral norm separations, maintaining the reputation of an educated man. Observance of business etiquette is one of the elements of a professional strategy.

The main function of teaching activities in the context of this research is to create a favorable environment for the development of teachers' research competence and it involves the following areas of evaluating differentiated activity of teachers:

1) Contribution to the teaching and guiding work of the department: development and implementation of a new course of lectures, new laboratory works with methodological support; development of plans and seminar programs on the new academic disciplines; preparation and publication of textbooks, use of modern technology in the educational process; introducing methods of business play into the educational process;

2) Contribution to the scientific-research work of the department: participation in R \& D; guidance of the research on regional and federal programs; an active part in organizing and conducting scientific conferences, exhibitions and other scientific events; publications of research articles, publication of monographs, textbooks; obtaining patents;

3) Contribution to the organization and conduct of students' scientific-research work: organization and carrying out competitions, roundtables, panel sessions, student conferences; preparation of students' works for national and international competitions as a scientific supervisor;

4) Contribution to the organizational work of the department: work as a person responsible for the activities area of the department (teaching and guiding, scientific and research work, professional guidance work); participation in the work of committees and councils at the Institute level.

5) Evaluation of the contribution to the achievements of the department and attitudes to their professional duties: maintaining work discipline, good performance of the basic functional responsibilities, attitude towards colleagues and students.

These trends for evaluating teaching permit with the help priorities selection guide the efforts of individual employees and the entire college team, to qualitatively perform research and educational tasks, which are most relevant for the college. The job evaluation system encourages teachers to improve personal qualifications in different forms, to actively participate in teaching and guiding, organizationally-pedagogical and scientific-research work. Increasing the importance of a particular type of employees' activity in the evaluation of their work in conjunction with the subsequent material incentives can be used as a powerful mechanism in college management.

Based on the component characteristics of the readiness for professional activity, on the specifics of innovative scientific-research and scientific-pedagogical activity, R. Kh. Gilmeeva developed a system-technological model of forming research competence of a teacher in secondary vocational education of teacher training specialization, the core of which is the structure of the stages of its formation, namely: adaptive, self-determinative, improving, and creative self-actualization, according to which and within which the process of systemically important research competence components acquisition is carried out, such as: 
- Person-centered (motivationally-personal);

- Substantive (cognitive-theoretic);

- Activity-based (constructive-designing);

- Reflexive (generalizing) (Gilmeeva, 2008).

\section{Results}

During the formation of research competence both a collection of all the components, and each component separately should be considered, since a change on one part of a competence does not solve the issue of changing the other. Despite their interdependence, each component has its own characteristics and relative independence.

Considering the proposed points of view on the component composition of the students and teachers' research competence formation, in the scope of this study we consider it appropriate to highlight the motivational-value, methodological-reflexive, operational-activity and emotional-volitional components of college teachers' research competence as conditions to improve their competitiveness:

1) Motivational-value component of developing a college teacher's research competence includes the motivation to succeed, clear goals and value systems, awareness of the importance of scientific-research activities, satisfaction with creative work in the innovative scientific-research and scientific-pedagogical activities process; willingness to participate in scientific conferences, seminars, publish the results of scientific-research works; awareness of the need for lifelong self-learning and self-development for a successful career.

2) Methodology-reflective component, which includes a college teacher's ability to use a teaching reflection to enrich the content of education by the results of scientific-research activities; ability to integrate knowledge on all types of professional activities into the scientific-research one; the ability to see the problem and formulate it properly; ability to determine the goals and objectives of the investigated problem, as well as the solutions, to determine methods, means and sequence of steps for conducting a research; the ability to form a hypothesis in the study of phenomena, laws, carry out the inductive formation of hypotheses on the basis of facts, phenomena known from life experience, obtained as a result of observations, and experiments; capability for analysis, synthesis and generalization of basic and applied investigations; ability to take risks.

3) Operational-activity component, comprising the following skills: the abilities to present themselves and the results of their scientific-research activities; to use the latest technologies for presentation of scientific-research activities; cooperate on all matters of research activities; apply and promote new knowledge; find a "dynamic balance" in solving scientific and research activity problems, as well as master the skills of planning, conducting experiments, processing and analyzing the experimental data; have a good command of methods for team management; be skilled in teaching and educational work; bring the results of scientific research to development results and implementation in practice; to conduct a patent search, search for information on innovative projects using modern information technologies; create and use software products for processing the obtained research results; have knowledge on the competition issues in today's conditions and apply them in scientific-research activities.

4) Emotional-volitional component, which includes capabilities to adjust to the expression of high moral qualities in scientific-research activities; show perseverance in aspiration to self-improvement in research activities; continuous self-development ability; resistance to stress; continuous professional development capability; pursuit of high quality final product of their work.

The presented components of a college teacher's research competence development, as a condition to improve his/her competitiveness, ensure the integrity and continuity of a competitive college teacher as a subject formation process, integrating research and professional activities.

\section{Conclusion}

Thus, the presented in the article basic components of teachers' research competence formation: motivational-value, methodological-reflexive, operational-activity and emotional-volitional components ensure the integrity and continuity of a competitive teacher as a subject formation process that integrates research and professional activities. Both a collection of all the components and each component separately must be considered, since a change in one part of a competence does not solve the issue of changing the other. Despite their interdependence, each component has its own characteristics and relative independence.

\section{References}

Berezhnova, E. V. (2007). Professional competence as a criterion for the quality of training of future teachers. In 
Competencies in education: Experience design (pp. 65-69). Moscow: Research and Innovation Enterprise "INEC".

Dvoretsky, S. I., \& Muratova, E. I. (2004). Scientific and pedagogical practice: The methodical recommendations on the organization of independent work of masters direction 551800 (p. 32). Tambov.

Gilmeeva, R. K. (2008). System-technological model of research competence of students of secondary vocational education teacher profile. Kazan pedagogical journal, 8(62).

Ivanov, V. G., Shaidullina, A. R., Drovnikov, A. S., Yakovlev, S. A., \& Masalimova, A. R. (2015). Regional Experience of Students' Innovative and Entrepreneurial Competence Forming. Asian Social Science, 11(1), $35-40$.

Khodenkova, O. P. (2011). Model of core competencies teacher of high school, formed under the influence of post-graduate education. Economics, 2, 169-173.

Khutorskoy, A. V. (2003). Key competences as a component of student-centered education paradigm. Education, 2, 58-64.

Morozova, N. N., \& Fadeeva, I. M. (2007). Model research competences of the person as a basis for the quality management of research activities in the university complex. University Management: Practice and Analysis, 5, 43-51.

Obukhov, A. S. (1999). Research activities as a method of forming a worldview. Education, 10, 158-161.

Plotnikova, N. I (2007). Educational competence in the structure of a distance course in English. Competencies in education: experience design (pp. 123-134). Moscow: Research and Innovation Enterprise "INEC".

Ryndina, V. (2011). Research competence as psycho-pedagogical category. Young scientist, 1, 228-232.

Shaimakova, J. B. (2009). The role of innovative competence in the development of competitive high school teacher (p. 248) (PhD Thesis, Tomsk).

Talyzina, N. F. (1986). Theoretical Foundations of the model development specialist (p. 65). Moscow.

Ushakov, A. A. (2008). Development of research competence of pupils of a comprehensive school in the conditions of profile training (p. 161) (PhD Thesis, Maikop).

\section{Copyrights}

Copyright for this article is retained by the author(s), with first publication rights granted to the journal. This is an open-access article distributed under the terms and conditions of the Creative Commons Attribution license (http://creativecommons.org/licenses/by/3.0/). 